\title{
Comunicação
}

[Communication]

\section{Proteinograma de caprinos da raça Pardo-Alpina infectados naturalmente por parasitos gastrintestinais}

[Proteinogram of Alpine goat naturally infected by gastrointestinal parasites]

\author{
S.Y. Fernández ${ }^{1,5}$, E.E.V. Jesus ${ }^{2}$, B.J.A. Paule ${ }^{4}$, R.S. Uzêda ${ }^{1}$, M.A.O. Almeida ${ }^{3}$, J.E. Guimarães ${ }^{3 *}$ \\ ${ }^{1}$ Aluna de graduação - EMEV-UFBA - Salvador, BA \\ ${ }^{2}$ Aluno de pós-graduação - ICS - UFBA - Salvador, BA \\ ${ }^{3}$ Escola de Veterinária - UFBA \\ Av. Adhemar de Barros, 500 \\ 40.170-110 - Salvador, BA \\ ${ }^{4}$ ICS - UFBA - Salvador, BA \\ ${ }^{5}$ Bolsista PIBIC/CNPq
}

As nematodioses gastrintestinais são freqüentes nas criações de caprinos na região Nordeste do Brasil, sendo mais encontrados os gêneros Haemonchus, Trichostrongylus, Strongyloides e Oesophagostomum (Girão, 1992).

O gênero Haemonchus destaca-se por sua ampla distribuição e prevalência nessa região (Charles, 1991) e por sua ação hematófaga, causando alterações nos constituintes sangüíneos, com diminuição na concentração de proteína total sérica, especialmente da albumina (Holmes, 1985). Nesses rebanhos ocorre também o coccídio do gênero Eimeria (Matos et al., 1987/88) com freqüência elevada 89,5\% (Martins e Menezes, 1999).

Alterações no perfil de proteínas séricas de caprinos infectados naturalmente por nematódeos gastrintestinais e Eimeria são pouco conhecidas . A análise desse perfil é importante na avaliação do estado nutricional, podendo indicar alterações metabólicas e auxiliar no diagnóstico clínico de diversas enfermidades (Barioni et al., 2001).

Poucos trabalhos relatam os valores de proteínas séricas em caprinos, destacando-se Castro et al. (1977) e Sharma et al. (2001), que encontraram médias de 6,7 e $7,25 \mathrm{~g} / \mathrm{dl}$ para a proteína total, respectivamente. Os primeiros autores também

Recebido em 30 de agosto de 2005

Aceito em 20 de março de 2006

*Autor para correspondência (corresponding author)

E-mail: jeugenio@ufba.br observaram média de $1,1 \mathrm{~g} / \mathrm{dl}$ para gamaglobulina e 1,2 para a relação albumina/globulina $(\mathrm{A} / \mathrm{G})$. No Brasil, as médias para proteína total, albumina, globulina e relação $\mathrm{A} / \mathrm{G}$ encontradas em cabras da raça Pardo-Alpina, clinicamente sadias, foram $6,29 \mathrm{~g} / \mathrm{dl} ; 3,51 \mathrm{~g} / \mathrm{dl} ; 2,78 \mathrm{~g} / \mathrm{dl}$ e 1,40 , respectivamente (Barioni et al., 2001). Resultado semelhante foi descrito por Fonteque et al. (2000) para proteína total $(6,29 \mathrm{~g} / \mathrm{dl})$, enquanto o valor da albumina foi de $2,41 \mathrm{~g} / \mathrm{dl}$.

O objetivo deste estudo foi avaliar o proteinograma de caprinos infectados naturalmente com parasitos gastrintestinais e a associação entre as variáveis do proteinograma.

Seis caprinos, da raça Pardo-Alpina, machos, criados em regime intensivo, foram acompanhados do primeiro ao $12^{\circ}$ mês de idade. Os animais receberam aleitamento artificial, três vezes ao dia, e suplementação, uma vez ao dia, com concentrado, capim-pangola (Digitaria decubens, Stent cv. Pangola) e Leucena (Leucaena leucocephala) até o segundo mês de vida. Do segundo ao quarto mês, permaneceram confinados, quando receberam apenas o concentrado e forragem. Posteriormente passaram para regime de semiconfinamento com a ração sendo fornecida uma vez ao dia.

Três tratamentos anti-helmínticos foram feitos entre o $7^{\circ}$ e o $10^{\circ}$ mês de idade, além de anticoccídio, administrado a cada três meses, durante o período do estudo. 
Amostras de sangue foram colhidas, mensalmente, para determinação de proteínas séricas, pelo método do biureto modificado, com leitura espectrofotométrica em $550 \mathrm{~nm}$ e separação eletroforética em gel de agarose, utilizando-se kit comercial $^{1}$. As fitas de agarose coradas com o amido Black foram lidas em densitômetro $^{2}$ com comprimento de onda de $520 \mathrm{~nm}$.

As contagens de ovos e oocistos (Gordon e Whitlock, 1939) e larvas por grama de fezes foram determinadas mensalmente. $\mathrm{Na}$ análise dos dados, utilizou-se o teste não-paramétrico de Spearman.

As médias e os desvios-padrão do proteinograma e exame coproparasitológico são apresentados nas Tab. 1 e 2 .

No período experimental, observou-se média dos valores de proteína total abaixo do limite inferior de normalidade, caracterizando hipoproteinemia, devido à diminuição de albumina, uma vez que essa fração mostrou-se sempre com seus índices inferiores quando comparados com os estudos de Castro et al. (1977) e Barioni et al. (2001). Resultados semelhantes foram encontrados por Jain (1993) em amostras séricas de caprinos que apresentavam elevada carga parasitária. Embora os valores encontrados de proteína total tenham sido inferiores, quando comparados com a literatura consultada, não houve correlação significativa entre essa variável e a contagem de ovos por grama de fezes.

A fração alfaglobulina apresentou valores dentro dos limites de normalidade (Fonteque et al., 2000). Castro et al. (1977) destacaram o aparecimento de duas bandas alfa (alfa1 e alfa2), diferentemente do que foi estabelecido neste trabalho, as quais foram encontradas na região betaglobulina (beta1 e beta2), semelhante ao descrito por Fonteque et al. (2000). De acordo com Kaneko et al. (1997), em relação à betaglobulina1, a média dos valores foi abaixo do limite inferior da normalidade, $0,90 \pm 0,1 \mathrm{~g} / \mathrm{dl}$, enquanto para a fração betaglobulina 2 observouse média acima do limite superior da

1 CelmGel (CELM - Cia Equipadora de Laboratórios Modernos - Barueri/S.P. - Brasil)

2 Densitômetro DS 35 (CELM - Cia Equipadora de Laboratórios Modernos - Barueri/S.P. - Brasil) normalidade, $0,4 \pm 0,02 \mathrm{~g} / \mathrm{dl}$. A média dos valores da fração gamaglobulina está dentro dos limites de normalidade sugeridos por Kaneko et al. (1997), 1,7 $\pm 0,44 \mathrm{~g} / \mathrm{dl}$, e acima dos citados por Castro et al. (1977), com exceção dos dois primeiros meses que apresentaram valores inferiores de gamaglobulina, o que é característico dos primeiros meses de vida dos animais (Jain, 1993).

$\mathrm{Na}$ relação albumina/globulina, a média foi inferior à encontrada por Castro et al. (1977) e Barioni et al. (2001), e, no sexto mês de idade, obteve-se o valor mais baixo. Essa divergência entre os valores pode ser atribuída às diferentes metodologias utilizadas pelos vários autores.

A média do OPG para a superfamília Strongyloidea foi $8.274 \pm 6.352$, nos 12 meses de estudo, com amplitude de variação de 6.352 a 24.143. Nas contagens de larvas infectantes, observou-se média de $4.613 \pm 4.134,1.193 \pm 449$ e $2.359 \pm 917$ para os gêneros Haemonchus, Trichostrongylus e Oesophagostomum, respectivamente.

Nas contagens de oocistos por grama de fezes (OOPG) do gênero Eimeria, encontrou-se média de $21.108 \pm 36.583$, com valor máximo de 133.000 e mínimo de 1.320 , observando-se elevada carga coccídica nos três primeiros meses de vida dos animais, com declínio do número de oocistos nos meses seguintes (Fig.1), por ser uma infecção autolimitante (Bomfim e Lopes, 1994).

No início do experimento, os animais apresentavam, em média, 15 dias de idade, verificando-se valor de proteína total no limite mais baixo, que pode ser atribuído à idade, semelhante ao que foi citado por Barioni et al. (2001), ou à infecção por coccídio.

O estudo conclui que caprinos Pardo-alpino, criados em regime intensivo, apresentam elevados níveis de infecção por coccídeos do gênero Eimeria até o terceiro mês de idade, e por nematódeos gastrintestinais, do $2^{\circ}$ ao $12^{\circ}$ mês, ocasionando hipoproteinemia por hipoalbuminemia sem alterações nas outras bandas do perfil eletroforético.

Palavras-chave: caprino, parasitos gastrintestinais, proteinograma 
Tabela 1. Média e desvio-padrão da proteína total, albumina, frações alfaglobulina, betaglobulina1, betaglobulina2 e gamaglobulina $(\mathrm{g} / \mathrm{dl})$ e relação albumina/globulina $(\mathrm{A} / \mathrm{G})$ de amostras séricas de caprinos machos, de acordo com a idade, criados em sistema intensivo

\begin{tabular}{|c|c|c|c|c|c|c|c|}
\hline \multirow{2}{*}{$\begin{array}{c}\text { Idade } \\
\text { (meses) }\end{array}$} & \multirow{2}{*}{$\begin{array}{c}\text { Proteína } \\
\text { total }\end{array}$} & \multirow{2}{*}{ Albumina } & \multicolumn{4}{|c|}{ Globulina } & \multirow{2}{*}{$\mathbf{A} / \mathbf{G}$} \\
\hline & & & Alfa & Beta 1 & Beta 2 & Gama & \\
\hline 1 & $4,9 \pm 0,6$ & $2,2 \pm 0,2$ & $0,6 \pm 0,1$ & $0,9 \pm 0,1$ & $0,4 \pm 0,1$ & $0,8 \pm 0,3$ & $0,9 \pm 0,2$ \\
\hline 2 & $6,3 \pm 0,3$ & $2,3 \pm 0,3$ & $1,8 \pm 1,0$ & $0,8 \pm 0,1$ & $0,8 \pm 0,3$ & $0,9 \pm 0,4$ & $1,0 \pm 0,3$ \\
\hline 3 & $5,7 \pm 0,8$ & $2,4 \pm 0,4$ & $0,5 \pm 0,3$ & $0,7 \pm 0,1$ & $0,4 \pm 0,1$ & $1,7 \pm 0,4$ & $0,8 \pm 0,2$ \\
\hline 4 & $5,1 \pm 1,4$ & $2,3 \pm 0,7$ & $0,5 \pm 0,1$ & $0,7 \pm 0,1$ & $0,5 \pm 0,2$ & $1,2 \pm 0,8$ & $0,8 \pm 0,2$ \\
\hline 5 & $5,6 \pm 0,9$ & $2,4 \pm 0,4$ & $0,5 \pm 0,2$ & $0,7 \pm 0,2$ & $0,4 \pm 0,1$ & $1,6 \pm 0,4$ & $0,7 \pm 0,1$ \\
\hline 6 & $4,2 \pm 0,7$ & $1,3 \pm 0,5$ & $0,6 \pm 0,1$ & $0,6 \pm 0,1$ & $0,4 \pm 0,2$ & $1,3 \pm 0,2$ & $0,5 \pm 0,1$ \\
\hline 7 & $5,8 \pm 0,7$ & $2,3 \pm 0,4$ & $0,5 \pm 0,1$ & $0,7 \pm 0,2$ & $0,5 \pm 0,1$ & $1,9 \pm 0,4$ & $0,7 \pm 0,1$ \\
\hline 8 & $6,7 \pm 0,4$ & $2,7 \pm 0,3$ & $0,7 \pm 0,1$ & $0,7 \pm 0,3$ & $0,5 \pm 0,1$ & $2,1 \pm 0,1$ & $0,7 \pm 0,1$ \\
\hline 9 & $5,5 \pm 0,2$ & $2,2 \pm 0,1$ & $0,7 \pm 0,1$ & $0,7 \pm 0,1$ & $0,5 \pm 0,1$ & $1,5 \pm 0,1$ & $0,7 \pm 0,1$ \\
\hline 10 & $6,2 \pm 0,4$ & $2,9 \pm 0,1$ & $0,6 \pm 0,1$ & $0,8 \pm 0,2$ & $0,5 \pm 0,1$ & $1,4 \pm 0,4$ & $0,9 \pm 0,1$ \\
\hline 11 & $6,0 \pm 1,7$ & $2,7 \pm 0,8$ & $0,6 \pm 0,1$ & $0,6 \pm 0,2$ & $0,5 \pm 0,2$ & $1,7 \pm 0,5$ & $0,8 \pm 0,0$ \\
\hline 12 & $6,4 \pm 0,3$ & $2,5 \pm 0,1$ & $0,8 \pm 0,2$ & $0,7 \pm 0,1$ & $0,4 \pm 0,1$ & $2,1 \pm 0,3$ & $0,7 \pm 0,0$ \\
\hline Total & $5,7 \pm 0,7$ & $2,4 \pm 0,4$ & $0,7 \pm 0,4$ & $\mathbf{0 , 7} \pm \mathbf{0 , 1}$ & $0,5 \pm 0,1$ & $1,5 \pm 0,4$ & $0,8 \pm 0,1$ \\
\hline
\end{tabular}

Tabela 2. Média e desvio-padrão de ovos (OPG) e larvas (LPG) por grama de fezes da superfamília Strongyloidea e por grama de fezes dos gêneros Haemonchus, Trichostrongylus e Oesophagostomum de caprinos machos, de acordo com a idade, criados em sistema intensivo

\begin{tabular}{|c|c|c|c|c|}
\hline \multirow{2}{*}{$\begin{array}{c}\text { Idade } \\
\text { (meses) }\end{array}$} & \multirow{2}{*}{$\begin{array}{c}\text { OPG } \\
\text { Strongyloidea }\end{array}$} & \multicolumn{3}{|c|}{ LPG } \\
\hline & & Haemonchus & Trichostrongylus & Oesophagostomum \\
\hline 1 & 0 & $448 \pm 976$ & $110 \pm 241$ & $110 \pm 255$ \\
\hline 2 & $100 \pm 283$ & $395 \pm 194$ & 0 & 0 \\
\hline 3 & $10.775 \pm 6.437$ & $9.400 \pm 5.299$ & $10 \pm 9$ & $310 \pm 590$ \\
\hline 4 & $9.571 \pm 6.289$ & $4.137 \pm 4.606$ & $20 \pm 17$ & $92 \pm 100$ \\
\hline 5 & $24.143 \pm 14.690$ & $11.070 \pm 4.983$ & $6.600 \pm 1.000$ & $11.842 \pm 2.034$ \\
\hline 6 & $10.033 \pm 2.946$ & $8.688 \pm 5.787$ & $110 \pm 91$ & $4.797 \pm 3.259$ \\
\hline 7 & $8.040 \pm 5.778$ & $10.560 \pm 3.918$ & $6.960 \pm 3.623$ & $9.180 \pm 3.506$ \\
\hline 8 & $3.080 \pm 3.324$ & $4.120 \pm 3.537$ & 0 & 0 \\
\hline 9 & $8.480 \pm 4.975$ & $1.230 \pm 739$ & $58 \pm 27$ & $448 \pm 332$ \\
\hline 10 & $9.760 \pm 7.277$ & $1.572 \pm 939$ & $90 \pm 27$ & $546 \pm 330$ \\
\hline 11 & $4.860 \pm 4.292$ & $1.980 \pm 1.649$ & $172 \pm 174$ & $122 \pm 106$ \\
\hline 12 & $10.440 \pm 9.560$ & $1.756 \pm 2.619$ & $186 \pm 179$ & $861 \pm 497$ \\
\hline Total & $8.274 \pm 5.488$ & $4.613 \pm 2.937$ & $1.193 \pm 449$ & $2.359 \pm 917$ \\
\hline
\end{tabular}

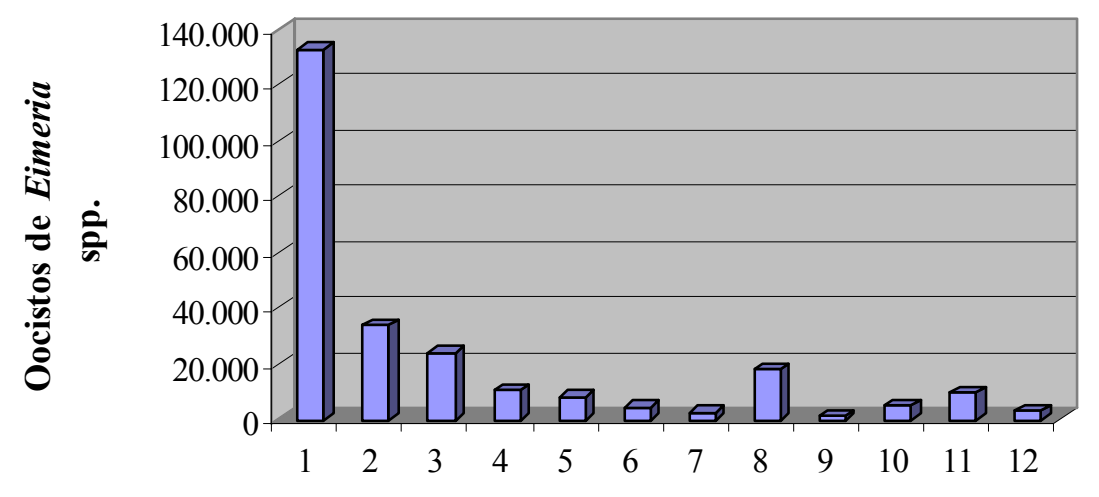

Idade (meses)

Figura 1. Média de oocistos por grama de fezes (OOPG) de Eimeria spp. de caprinos machos, com um mês a um ano de idade, criados em sistema intensivo. 


\begin{abstract}
The proteinogram of six 12 month-old Alpine goats, intensively raised and naturally infected by gastrointestinal parasites, was evaluated. Blood and feces samples of each animal were monthly collected. Total serum protein and their fractions were determined by agarose gel eletrophoresis, using Tris buffer, pH 9.2. The identified protein fractions were albumin, alfa-globulin, betal-globulin, beta2globulin and gama-globulin, whose average and standard deviation ( $g / d l)$ were, respectively: $2.35 \pm 0.39$, $0.69 \pm 0.36,0.70 \pm 0.08,0.48 \pm 0.08$ and $1.52 \pm 0.41$. It was not observed significative correlation $(P>0.05)$, according to the Spearman non-parametric test, either between the Strongyloides eggs count per gram of feces or the Haemonchus spp. larval count per gram of feces and the fraction electrophorectly variable.
\end{abstract}

Keywords: goat, gastrintestinal parasites, proteinogram

\section{REFERÊNCIAS BIBLIOGRÁFICAS}

BARIONI, G.; FONTEQUE, J. H.; PAES, P.R.O. et al. Valores séricos de cálcio, fósforo, sódio, potássio e proteínas totais em caprinos fêmeos da raça parda alpina. Ciên. Rural, v.31, p.435-438, 2001.

BOMFIM, T.C.B.; LOPES, W.G. Levantamento de parasitos gastrintestinais em caprinos da região serrana do estado do Rio de Janeiro. Rev. Bras. Parasitol. Vet., v.2, p.119-124, 1994.

CASTRO, A.; DHINDSA, D.S.; HOVERSLAND, A. S. et al. Serum proteins and protein electrophoretic pattern in normal pygmy goats. Am. J. Vet. Res., v.38, p.665-667, 1977.

CHARLES,T.P. Epidemiologia e controle dos nematódeos de caprinos do Brasil. In: SEMINÁRIO BRASILEIRO DE PARASITOLOGIA VETERINÁRIA, 7., 1991, São Paulo. Anais... São Paulo: Colégio Brasileiro de Parasitologia Veterinária, 1991. p.65-68.

FONTEQUE, J. H.; PAES, P.R.O.; BARIONI, G. et al. Comparação do perfil eletroforético das proteínas séricas em caprinos fêmeas as raça Parda Alpina. In: CONFERÊNCIA SUL AMERICANA DE MEDICINA VETERINÁRIA, 2000, Niterói. Suplemento... Niterói, 2000. p.211.

GIRÃO, E. S. Testes alternativos para o controle da verminose dos caprinos. Teresina: EmbrapaUepae Teresina, 1992. 10p.
GORDON, H.M.; WHITLOCK, H.V. J. Counc. Sci. Ind. Res., v.12, p.50-52, 1939.

HOLMES, P. H. Pathogenesis of trichostrongylosis. Vet. Parasitol., v.18, p.89101, 1985.

JAIN, N.C. Essentials of veterinary hematology. Philadelphia: Lea \& Febiger, 1993. p.349-350, 361-366.

KANEKO, J.J.; HARVEY, J.W.; BRUSS,M.L. Clinical biochemistry of domestic animals. 5.ed. California, 1997. 932p.

MARTINS FILHO, E.; MENEZES, R.C.A.A. Ocorrência de parasitismo por coccídio do gênero Eimeria em caprinos do semi-árido paraibano. In: SEMINÁRIO BRASILEIRO DE PARASITOLOGIA VETERINÁRIA, 11.,.1999, Salvador. Anais... Salvador: Universidade Estadual de Santa Cruz, 1999. p 217.

MATOS, M.S.; CALDAS, E.M.; FITERMAN, I.R. Eimeria parva, E. pallida e E. arloingi em caprinos, Bahia, Brasil. Arq. Esc. Med. Vet. UFBA., v.1, p.61-69, 1987/88.

SHARMA, D.K.; CHAUHAN, P.P.S.; AGRAWAL, R.D. Changes in the levels of serum enzymes and total protein during experimental haemonchosis in Barbari goats. Small. Rum. Res., v.42, p.119-123, 2001. 